Document downloaded from:

http://hdl.handle.net/10251/81797

This paper must be cited as:

Tomas Miquel, JV.; Expósito Langa, M.; Nicolau Juliá, D. (2016). The influence of relationship networks on academic performance in higher education: a comparative study between students of a creative and a non-creative discipline. Higher Education. 71(3):307322. doi:10.1007/s10734-015-9904-8.

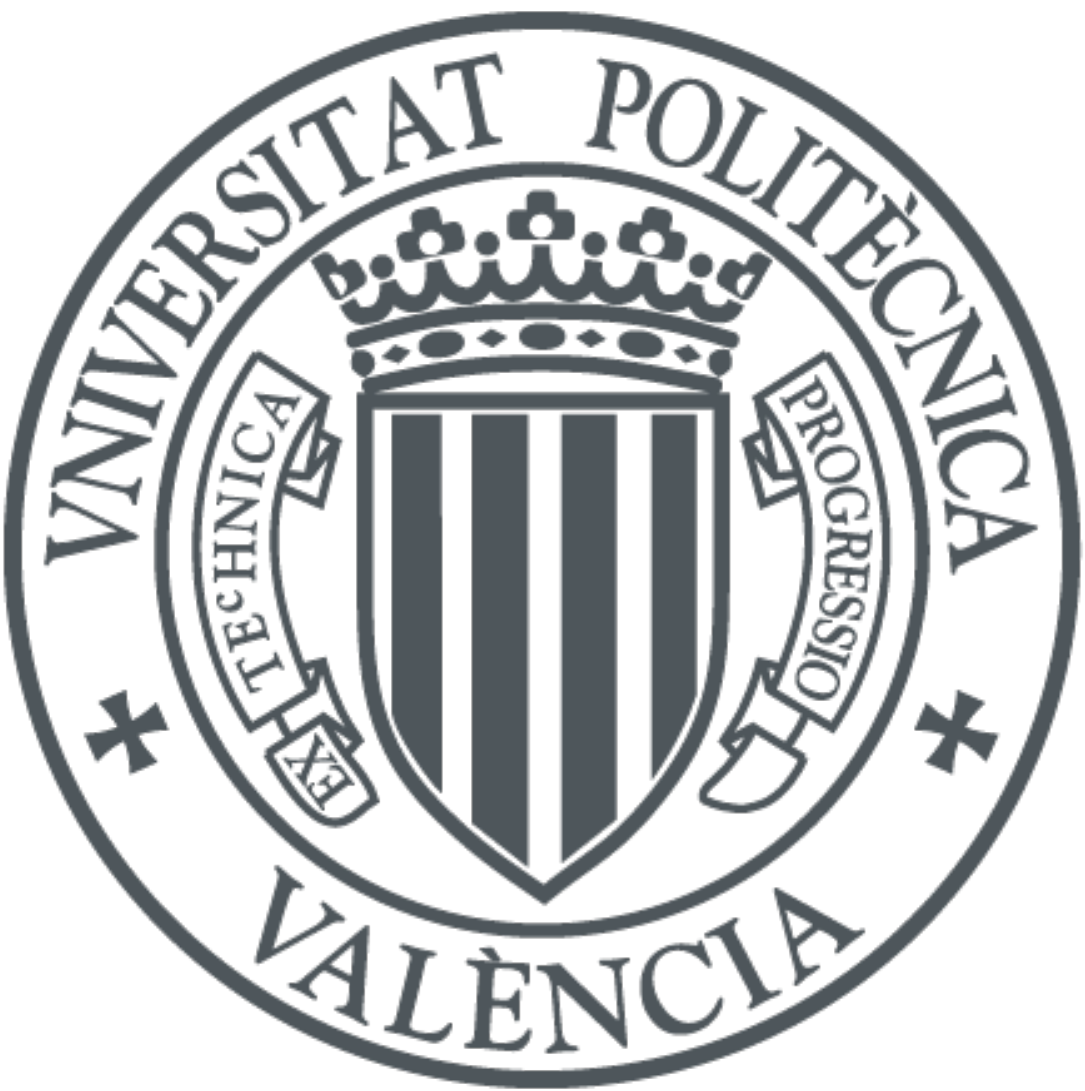

The final publication is available at

http://dx.doi.org/10.1007/s10734-015-9904-8

Copyright Springer Verlag (Germany)

Additional Information 


\section{THE INFLUENCE OF RELATIONSHIP NETWORKS ON ACADEMIC PERFORMANCE IN HIGHER EDUCATION. A COMPARATIVE STUDY BETWEEN STUDENTS OF A CREATIVE AND A NON-CREATIVE DISCIPLINE}

\section{Introduction}

The study of the factors influencing the academic performance of undergraduate students is a research topic that has drawn the attention of educators and practitioners in recent decades. Traditionally, factors related to personal skills and motivation have been used to explain the performance of students (Rizzuto et al. 2009). However, in recent years scholars have also recognized the influence on this performance of students social interactions, independent of their course work or instruction (Johnson and Johnson 1993; Baldwin et al. 1997).

Social ties developed by undergraduate students create informal peer networks which help them to establish friendship and trust-based relationships and exchange information and knowledge. These interactions have long been recognized as one of the critical factors in facilitating the learning process (Gašević et al. 2013) and may enhance students performance in at least two ways (Baldwin et al. 1997). Firstly, they improve cognitive processing (e.g., verbalizing information to others or restructuring information) and, secondly, they create an emotional or intellectual climate conducive to learning (e.g., peer motivation or anxiety reduction). This diversity of educational benefits derived from social learning has resulted in the widespread adoption by practitioners of socially interactive and collaborative pedagogies (Dawson 2008).

Social ties have been shown in the literature to be positively associated with academic performance. Nevertheless, recent contributions have looked more closely at student networks arguing that when predicting students achievement and engagement in school, not only is the size of the social network important, but also the nature and content of the ties (Smith and Peterson 2007). Thus, academic links, namely those related to knowledge exchange, may have a stronger positive influence on student performance than those more related to friendship and trust.

Although current literature has shed some light on the influence of relational aspects in higher education, we consider that there are still some important questions to be addressed.

In this sense, we believe that the studies carried out to date do not look deeply enough at the relational aspects when using Social Network Analysis (SNA) techniques (Wasserman and Faust 2007) to study the influence of student position in these networks on their academic performance. This is especially relevant when diverse disciplines of study that require different student skills and competencies in terms of creativity and innovative capacity are addressed. Current literature assumes that students academic relationships have a positive influence on their performance at the university. However, in our opinion, there is a problem related to the generalization of these conclusions. For example, individuals in creative contexts may suffer from high levels of internal relationships (Cattani and Ferriani 2008). The sharing of redundant information and the difficulties in abandoning existing ideas and exploring new ones are some of the types of problems identified for these highly connected actors (Morrison and Rabellotti 2005; Schilling 2005). On this basis, we consider that there are still important questions in the literature on students' social networks in higher education to be addressed.

This work attempts to fill this gap and to contribute to a better understanding of the role of social ties in different academic contexts by exploring through SNA techniques the connection of undergraduate students ties to academic performance in two bachelor's degrees with divergent contents and competence profiles in terms of creativity outcomes.

To proceed with the empirical study, we selected students from the Bachelor's degrees in Industrial design engineering and Business administration and management, both from the Campus of Alcoy of the Universitat Politècnica de València. Specifically, our study focused on 154 final year students.

The work is structured as follows. Firstly, the theoretical framework is developed and the research questions and hypotheses are stated. Next, the methodology and the empirical study carried out are described and finally, the main findings, conclusions and implications of the work are discussed. 


\section{Theoretical background and hypotheses}

\section{Student networks and academic performance}

Over recent decades, higher education in many developed countries has shifted from elite to mass education. More and more students are deciding to go to universities and receive degrees before entering the work force (Martens and Starke 2008). At the same time and accompanying this growth in higher education, the diversity among the student population is also increasing (McKenzie and Schweitzer 2001). Students from different countries, social and cultural backgrounds, with different experiences and needs and varying levels of education have created a new complex scenario in universities where traditional teaching methodologies may be inadequate. Under this new context, higher education institutions have been challenged not just to recognize this diversity of needs but also to deal with this changing and heterogeneous population of students by providing them the support and help needed to ensure a reasonable chance of success (Power et al. 1987).

Arising from these changes, several contributions in recent decades have attempted to undertake prospective studies of the predictors of academic success in these higher education contexts. Much of this literature draws on student ability and motivation as the most significant factors (Meece et al. 2006; Kassim et al. 2008; Pekrun et al. 2009), while less attention has been given to the social factors that shape performance in academic-settings (Rizzuto et al. 2009). Nevertheless, social relationships are highlighted by many scholars as one of the critical factors that influence the students' learning process (Gašević et al. 2013). In fact, these learning processes do not arise in an individual context but through interpersonal communication processes (Lave and Wenger 1991; Haythornthwaite 2002).

The influence of social ties has grown in importance in the university context with increasingly populated and heterogeneous classrooms and consequently where personal contact between teacher and student is becoming more limited. Thus, students are looking more to their colleagues for the help and support necessary to succeed in this highly competitive context, especially those at high risk of not fulfilling their academic potential.

Several studies have analyzed the association between social ties and academic performance. Most of them confirm the growing importance of this relationship (Baldwin et al. 1997; Thomas 2000; Yang and Tang 2003; Yuan et al. 2006; Smith and Peterson 2007; Rizzuto et al. 2009; Hommes et al. 2012; Gašević et al. 2013). Consequently, social network position is expected to be a relevant predictor of academic performance of undergraduates in higher education.

However, when deepening this relationship, not all ties have the same degree of influence on student academic performance. Thus, as Smith and Peterson (2007) indicate, when predicting academic performance and involvement, it is not just the size of the social network but also the content of the ties.

Therefore, one must distinguish between the different types of relationships that may occur between students in a class, since a purely formal relationship will not have the same influence as a friendship tie that presupposes some kind of social interaction that persists beyond the academic context.

The literature identifies two main types of networks among students (Ibarra 1993). Firstly, there are the instrumental or academic networks which are more related to the exchange of knowledge between students. According to Chen et al. (2012), these ties provide support to the student in the form of sharing notes, jointly solving complex problems and allowing group study, all of which are needed for successful completion of the program. In fact, Thomas (2000) stated that the structural properties of the academic network could be interpreted as indicators of the extent to which students are integrated into the life of the faculty, campus or university. The formation of an academic network is consistent with the idea of a learning community where common understandings of the practices and collective learning can take place (Stassen 2003).

Apart from academic networks, we also find expressive or friendship networks which are more linked to affection, emotions and attachment. These ties cover relationships that involve the exchange of friendship and trust and are generally more related to things that have nothing to do with class. With these ties, students often share values, habits and other characteristics and bond through mutual reinforcement of those similarities (Smith and Peterson 2007). Friendship ties are often considered as a source of psychosocial support (Ibarra 1995) that may help in dealing with the stresses and strains of negotiating a demanding educational program (Baldwin et al. 1997). However, in other contributions, these ties are considered more a way to suppress successful learning, since the friendships may prevent students from developing new relationships and being exposed to constructive critiques (Smith and Peterson 2007).

In this double scenario of student networks (academic and friendship), the literature has studied how the centrality of the students in these networks, namely the extent to which students have a strategic position 
(Freeman 1979), has influenced their academic performance and satisfaction. Several contributions have stated the positive influence of the centrality in academic networks on performance (Baldwin et al. 1997; Yang and Tang 2003; Cho et al. 2007; Smith and Peterson 2007; Hommes et al. 2012). Students who occupy a central position in the academic network are able to accumulate information, knowledge and experience related to the tasks and work performed. In consequence, they are likely to perform better than their peers who are not located in such central positions.

With respect to friendship networks, there is some controversy about the influence they may have on performance. Some authors argue that these ties are more connected to student satisfaction and emotional balance (Baldwin et al. 1997; Yang and Tang 2003), without seeing evidence of its association with performance. Others authors have stated a minor positive influence (Hommes et al. 2012), whereas others have even posed a negative effect (Smith and Peterson 2007).

While the influence of friendship ties on performance may require further analysis, in our research we will focus on the student's academic network since it is more connected to student performance and the aim of our study.

\section{The influence of the discipline of study: creative and non-creative contexts}

The influence of the discipline studied by undergraduate students on the relationship between social ties and student achievement has received little attention in the literature. As it is considered more a predictor of student performance (Kornbrot 1987; Hoskins et al. 1997), its analysis in other contexts has been very limited to date. In our case, our interest centers on studying whether the positive relationship stated in the literature between academic relationships and performance behaves similarly throughout the different disciplines of study, especially when these are connected to creative outcomes.

Over recent decades, higher education has focused on the definition of the set of competencies and skills that are expected to be acquired by students of the different studies offered. While some of these skills are highly recommended in all disciplines, such as teamwork or interpersonal communication skills, others are more specific and connected to a concrete area of study. Among the latter, we find creativity and innovation skills whose development is related, among others, to disciplines such as art or engineering (Costantino et al. 2010). In these areas, successful students demonstrate, along with other skills, the ability to generate and develop new ideas.

Creativity is often referred to as the production of outcomes that can be reliably assessed as novel or valuable by expert observers (Amabile 1996). In this sense, it is derived from the interplay between the individual creative act and the social context that decides whether or not that act is endorsed and legitimated.

Social networks play an important role in this interaction. On one hand, the position of the individuals in the social network regulates access to new information and the ability to generate new ideas. On the other hand, that position also influences the capability to obtain the support from others and thus overcoming the initial illegitimacy of their ideas and leveraging shared thought and action (Cattani and Ferriani 2008).

On this basis, Cattani and Ferriani (2008) indicate, in the context of the Hollywood film industry, that core/periphery position of individuals in their networks may influence their creative outcomes. In the following paragraphs we look more deeply into this question using Cattani and Ferriani's approach and consider its application in higher education scenarios.

\section{Research hypotheses}

Individual networks can be represented on the basis of a core/periphery network structure (Borgatti and Everett 1999). The notion of core/periphery is based on the fact that many real world networks can be divided into two distinct sub-groups of actors that can be identified by the type and number of connections. This model is characterized by a cohesive clique of densely interconnected core actors surrounded by a fringe of peripheral actors that tend to establish loose links with the core firms and virtually no connections with other peripheral firms. While core/periphery structures have been used to model social networks in academic contexts including groups of lecturers (Beck et al. 2003) or research networks (Leydesdorff and Wagner 2008; Kronegger et al. 2011), they have not been used to date to represent student networks, although recent literature has suggested their suitability for being applied in these contexts (Biancani and McFarland 2013: 185).

In this model, core nodes are intensely embedded in the social system and therefore tend to share ideas and habits more closely. These actors have great exposure and access to sources of knowledge, support and legitimacy, but may have difficulty in obtaining new ideas and escaping the pressures of performing tasks and work under the rules established in the network. On the other hand, the periphery is populated by nodes that are tied to the core by looser linkages and are scarcely connected to each other. These actors reside in the boundaries 
of the network having a poor visibility and social engagement with those in the core (Cattani and Ferriani 2008).

The literature has stressed the differences in creative outcomes for individuals that may stem from their location in both core and periphery (Perry-Smith and Shalley 2003; Uzzi and Spiro 2005; Cattani and Ferriani 2008). In fact, according to Cattani and Ferriani's study, the social network influence on the individual creative performance can be characterized by a core/periphery trade-off.

More central actors are better able to acquire information and resources from throughout the network thereby obtaining a more powerful position to influence and benefit from network activities (Raven 1965). Moreover, research has stated that these actors are not only likely to enjoy a greater number of communication channels but also are more active in using these channels (French and Snyder 1959). Core positions also increase the chance that a creative outcome could be recognized and legitimated. Since core individuals are deeply immersed in their social system, they can leverage their credibility among other individuals (Cattani and Ferriani 2008). However, the high integration of core nodes can lead to a higher probability in accessing the same information sources and in turn sharing redundant information and knowledge (Morrison and Rabellotti 2005), to be exposed to different sources of stress and conflict (Perry-Smith and Shalley 2003) and to some difficulties in abandoning existing ideas and exploring new ones (Schilling 2005).

A peripheral position suggests more reduced access to the knowledge sources existing in the core, but also a relevant set of connections outside the network that can facilitate creative outcomes through accessing fresh knowledge sources. Outside connections can provide the peripheral actor with approaches used in related but different areas (Perry-Smith and Shalley 2003). Peripheral actors are able to avoid the homogenizing influences typical of an established institutional framework and hence consider divergent ideas without the anxiety of contrasting accepted norms of the context (Cattani and Ferriani 2008).

Therefore, individuals closer to the core, that is, showing high level of coreness, have greater access to the relevant sources of knowledge, support and legitimacy of their network, but may show a similar orientation in performing their jobs (Sparrowe et al. 2001) and find it difficult to see things broadly, explore creative ideas and escape the pressures to conform to the established norms (Perry-Smith and Shalley 2003). Conversely, peripheral actors are more likely to contribute with new ideas to the network, but may lack the visibility and acceptance needed to achieve wider acknowledgment of their work.

Hence, it is expected in creative scenarios that academic performance will be higher among students of the network who are located in an intermediate position between core and periphery. They benefit from both the knowledge flows available in the core and the external sources that enhance their creativity. Furthermore, students in these positions do not experience the same level of social pressure to conform and therefore are more open to opportunities from which creative ideas spring.

However, in non-creative scenarios, where creative outcomes are not extensively considered or valued, core positions may provide students with knowledge, experience and extensive support. In fact, they are in a more powerful position to benefit from network activities. In contrast, the benefits of being located in the periphery are not appreciated here.

In consequence, the type of discipline studied may explain why students with a higher coreness in the academic network can show lower performance than others with lower coreness values. In non-creative disciplines or studies where creativity and innovation can have minor relevance, the location of the students closer to the core of the academic network can provide them with new knowledge and experiences that may enhance their performance. Therefore, the following hypothesis is proposed:

H1: In non-creative contexts, there is a positive linear relationship between the student coreness in the academic network and academic performance.

Nevertheless, in creative scenarios, an excessive coreness in the academic network can cause a lock-in, thus dampening exposure to new ideas and decreasing the benefits of being located in those areas. The non-linear inverted U-shaped relationship is the function that best captures expectations based on the argument. Consequently, the following hypothesis is also proposed:

$\mathrm{H} 2$ : In creative contexts, there is an inverted U-shaped relationship between the student coreness in the academic network and academic performance.

\section{Method}

The Campus of Alcoy of the Universitat Politècnica de València (UPV) enrolled roughly 2,400 students in academic year 2013-2014 and offered 6 Bachelor's degrees and 3 official masters. Among these qualifications, we find the Bachelor's degree in Business administration and management (BDBAM), which 
enrolled 364 students distributed over 4 years. BDBAM studies are geared towards training professionals able to manage, advise and evaluate business organizations. Graduates receive a complete grounding in management and organization, enabling them to perform tasks of responsibility in the various departments in the company (operations, human resources, sales, finance, etc.).

Furthermore, UPV also offers the Bachelor's degree in Industrial design engineering (BDIDE), which enrolled 346 students also split over 4 years. This degree differs significantly from BDBAM in terms of the approach and the learning objectives pursued. Here, innovation and creativity are present throughout the course in all projects and work carried out. Accordingly, BDIDE is aimed at training students able to develop their work in a context of leadership and management of the whole product life process, from idea generation, through production and product release, to the environmental impact assessment at the end of product life.

\section{Sample and data collection}

The sample analyzed has focused on students enrolled in the fourth year in two different degrees especially in terms of creativity and innovation: a less creative context represented by BDBAM (hereinafter referred to as "Non-Creative Discipline" or "NCD") and a setting more connected to innovative practices represented in this case by BDIDE (hereinafter referred to as "Creative Discipline" or "CD").

The students addressed are in the final year of the degree with a set of consolidated friendship and academic relationships and presumably at its point of greatest intensity. The completion of the fieldwork was developed through a roster recall method applied to all students during February of 2014. This technique entails presenting to each of the students a full list of the students enrolled in the course. Then, they are asked to indicate the academic and friendship relationships they have with their peers. In turn, this information was supplemented with secondary data such as work and joint activities developed in various subjects to increase their validity (Yin 1989). At the end of the process a total of 76 responses for NCD and 78 for CD were obtained, all of them valid, which means that all students have participated in this study.

Finally, in order to obtain a more detailed description of the sample, Table 1 provides a list of measures related to the group of students analyzed.

INSERT TABLE 1 ABOUT HERE

\section{Measurement}

\section{Academic performance}

In order to operationalize this variable, we used the grade average obtained by each student in the different subjects studied in the first semester (September 2013 to January 2014) of the fourth year.

\section{Knowledge / friendship networks coreness}

Network coreness refers to the degree of closeness of each node to a core of densely connected nodes observable in the network (Borgatti and Everett 1999). In order to operationalize this variable, we applied SNA techniques. These provide a tool to explore the structural properties of a network and encompass theories, models, and applications that are expressed in terms of relational concepts or processes (Wasserman and Faust 2007). The application of these techniques in the field of higher education is a relatively recent phenomenon (Biancani and McFarland 2013), although educational research is increasingly drawing on them (Gašević et al. 2013).

The application of SNA techniques requires first the construction of both the academic and friendship networks of ties. Therefore, in order to proceed with this step, we followed the procedure described in Smith and Peterson (2007). Students were shown the entire roster of classmates (Erickson et al. 1981) and then asked to indicate what type of relationship had been established, if any, with each classmate listed. Specifically, 2 questions were examined: "With whom of the listed classmates have you recently maintained friendship relationships?" and "Who of the listed classmates have you helped or provided relevant knowledge for the development of the classes, work or projects of the different subjects in the last semester?". 
In order to measure the network coreness, we used UCINET v.6 software (Borgatti et al. 2002). Two estimates were calculated for each network actor, coreness in the academic network and coreness in the friendship network. Although we only used the former to contrast Hypotheses 1 and 2, we applied the latter to control results.

\section{Control variables}

In line with other contributions, such as Thomas (2000), Smith and Peterson (2007) or Huang (2009), we have added some control variables in our study, namely student gender and age.

\section{Results}

In Tables 2 and 3, we present basic descriptive statistics and Pearson's correlations for all variables in both samples. The correlations matrix shows a correlation between academic performance and academic network coreness both in NCD and CD providing some initial evidence to support Hypotheses 1 and 2. Academic network coreness also relates positively to friendship network coreness thus suggesting that there may exist a certain positive relationship between the position of the students in the academic network and their position in the friendship network. Similar results are found in other contributions as Smith and Peterson (2007) or Chen et al. (2012). Finally, there is no correlation between the control variables and academic performance.

INSERT TABLE 2 ABOUT HERE

INSERT TABLE 3 ABOUT HERE

\section{Descriptive results}

Before testing the hypotheses, we present a descriptive analysis of the networks studied and the extent they conform to a core/periphery structure.

In Figure 1, academic networks in both NCD and CD samples are presented. In each graph, a node represents a student. A line between two nodes indicates the presence of a relationship between them. The larger the size of the node, the higher the level of coreness of the student.

Visually, the graphs reveal some important insights. Both contexts, NCD and CD, reflect similar structures and basic behavior, including the fact that there is no isolated student in any of the networks analyzed. Also, students extensively develop academic connections between each other.

The underlying data in Table 4 confirms the impression gained by visual inspection. The density of the academic network in the creative discipline is similar to the density in the non-creative discipline. Additionally, density figures confirm a well-communicated network of peers. Alternatively, we have studied the existing concentration of ties between students within both networks via the Gini index, that is, whether some students maintain more ties than others, which would be an indicator of the presence of internal heterogeneity. Overall, Gini index values indicate certain heterogeneity in the number of ties established by each student in both samples. 
At this point it would be interesting to assess whether, as predicted by recent literature (Biancani and McFarland 2013), a core/periphery configuration emerges out of these student networks. Testing for this means verifying to what extent NCD and CD networks reproduce an ideal core/periphery setting (Borgatti and Everett 1999). This can be addressed by using different goodness-of-fit measures. We have applied in this case correlation and density measures to test results robustness. UCINET v.6 results show starting and final fitness coefficients of 0.507 for the NCD sample and 0.567 for the CD sample. This measurement varies from 0 to 1 , where 1 represents a perfect fit with the ideal model and 0 represents a total dissimilarity. Although far from perfect, these correlations have a strong fit with the ideal core/periphery model (Borgatti and Everett 1999: 381).

Densities within groups are shown in Table 5. In both samples, densities are also in line with previous results. Thus, we can observe intense core-to-core interactions, especially when compared to periphery-to-periphery ties. The core-to-periphery and periphery-to-core linkages are, as expected, rather sparse.

INSERT TABLE 5 ABOUT HERE

These results confirm the predictions of the recent literature about the structure of student networks thus allowing us to continue with the analysis and the use of core/periphery measures.

\section{Regression results}

To test the hypotheses we ran a regression analysis to assess the explanatory power of the set of variables. The model analyzed is as follows:

Model: Academic performance $=\alpha_{1}+\beta_{1}$ Academic network coreness $+\beta_{2}$ Academic network coreness ${ }^{2}+\beta_{3}$ Friendship network coreness $+\beta_{4}$ Student gender $+\beta_{5}$ Student age

The model was tested both in NCD and CD samples. The above model in the NCD scenario is related to Hypothesis 1 and examines the positive relationship between the student coreness in the academic network and academic performance in non-creative contexts. On the other hand, the model in the CD sample is related in this case to Hypothesis 2 and tests the presence in creative and innovative settings of a relationship between student coreness in the academic network and academic performance in the form of an inverted U-shaped function. The curvilinear model was also tested in the NCD sample to control for quadratic responses.

Regarding the NCD sample and in order to statistically justify the direct relationship between academic network coreness and academic performance, we ran a regression analysis. The results of this analysis can be seen in Table 6. An ANOVA analysis confirms the possible existence of a significant correlation between variables. In our case, the F-statistic result confirms the significance of the variance of the dependent variable through the model. Also, results confirm the significant relationship between academic network coreness and academic performance. It is also worth noting that the sign of the academic network coreness is positive, thus indicating an increasing linear relationship. Hence, Hypothesis 1 receives support. On the other hand, as expected, the quadratic relationship between academic network coreness and performance is not supported.

In regard to control variables, results also confirm a significant relationship, here with a negative sign, between the variable friendship network coreness and performance in the NCD sample. This result is in line with previous contributions as Smith and Peterson (2007). While our study is not aimed at analyzing the influence of friendship networks on academic performance and is only intended for control purposes, the result obtained has important consequences and can lead to possible future contributions. In this vein, this result brings to light the fact that friendships may take time and energy and people may have limits as to how many strong and 
interconnected relationships they can maintain. The time and energy required by friendships may compete with the effort it takes to perform well academically (Smith and Peterson 2007).

Furthermore, Table 6 also shows that neither gender nor age is significantly associated with academic performance. While these variables are significant in some studies, as shown by Allen and Haniff (1991) or Dayioğlu and Türüt-Aşik (2007), in other contributions the results are inconclusive (Hoskins et al. 1997; Smith and Naylor 2001). In consequence, more future research is therefore needed to monitor how gender and age may influence these relationships (Thomas 2000; Smith and Peterson 2007).

INSERT TABLE 6 ABOUT HERE

Concerning the test in the CD sample, we ran a curvilinear regression analysis to statistically justify the proposed inverted $U$ shape in Hypothesis 2. Results in Table 6 confirm the significant relationship between academic network coreness and performance adjusted to the inverted $U$ form. The regression coefficients, both academic network coreness and academic network coreness squared have some significance. It is also worth noting that the sign of the latter is negative, denoting an inverted U-shaped relationship. This means that increasing values of the academic network coreness variables run parallel with the increasing values for academic performance; however, at a certain point, additional increases are negatively associated with attainment. Thus, an excess of coreness erodes the positive effect of knowledge ties. In consequence, Hypothesis 2 is also supported. On the other hand, none of the control variables had a significant effect in this scenario.

Finally, in order to gain more insight into the effects in the NCD and CD samples, we plot the relationships in Figure 2.

INSERT FIGURE 2 ABOUT HERE

\section{Conclusions}

In this paper we have intended to contribute to the debate on the role that relationships with peers have in student achievement. To this end, we compared the influence of social ties on performance in two different Bachelor's Degrees characterized by different requirements in terms of creativity-related skills and competencies.

Although the initial descriptive analysis reveals the existence of remarkable similarities between both contexts in terms of their network structural characteristics, this conclusion varies considerably when academic performance is introduced in the study. Thus, our results confirm a different influence of the network position of the student on performance depending on the context addressed. In non-creative scenarios, the closeness of the students to the core of relationships of their academic network allows them to be directly exposed to several sources of support and knowledge that may help them to better perform academically. On the other hand, in creative contexts a high level of coreness may prevent students from the exposure to connections outside the network and from escaping the pressures of performing their work under the established rules thereby reducing the possibility of producing creative outcomes. In these settings, being in an intermediate position between core and periphery enables students to benefit from both the sources of knowledge and legitimacy available in the core and the external sources that help them to improve creativity. In consequence, in creative scenarios the relationship between academic ties and student performance is based on the form of an inverted U-shaped curve.

These results are fairly consistent with past research which had proposed a positive relationship between social ties and academic performance (among others, Baldwin et al. 1997; Smith and Peterson 2007; Hommes et al. 2012). However, these previous works use similar social network analysis frameworks to operationalize student 
connectedness that do not go beyond the traditional centrality measures such as degree or closeness (Freeman 1979). Moreover, they did not contemplate the specific characteristics of the different disciplines of study, especially when creative contexts are addressed. Therefore, we consider that there are two main implications of our work for educational research. On the one hand, our study confirms the possibility of modeling student relationships from the scope of a core/periphery model, as suggested by recent literature (Biancani and McFarland 2013). This model provides an alternative and enriching framework to represent and analyze the structure of relationships in student networks. Thus, our results may pave the way and encourage researchers to the development of new contributions which, on the basis of a core/periphery model, can deepen the understanding of the role of student relationships in higher education. On the other hand, while we have no doubt about the benefits of student relationships, the influence of the context should not be overlooked. As our results reveal, the role of creativity in the discipline of study can influence the relationship between academic ties and student performance.

Furthermore, we believe that our analysis may also suggest implications for policy and strategy. Our findings might help guide universities on the development of activities aimed at enhancing student connectedness but with different objectives depending on the role of creativity in the discipline of study. Therefore, while in noncreative disciplines activities should be designed to encourage the development of student relationships, especially between course peers, in creative contexts activities should help students develop a portfolio of academic relationships with both course peers and external sources of knowledge such as students from other disciplines or companies and institutions.

Finally, this research suffers from some certain limitations. Firstly, we have not considered the influence of the structure and composition of student working teams on the academic performance of each of their members. But, as argued by recent literature, working teams internal composition may compensate the lack of relational capabilities of some of their members (Guimerà et al. 2005; Cattani and Ferriani 2008). Secondly, our research has modeled the disciplines of study as being either creative or not creative. While this enables analysis and improves understanding, the linkage of the different university studies with creativity in real scenarios is closer to a continuum. Thirdly, student's connectedness is a topic that requires more research. Therefore, other issues on connectedness are a valuable addition to quantitative analysis to understand more thoroughly how students rely on their peers. For example, some questions remain: how non-creative studies may not experience the trouble of having a network that is too big or how students can limit their network automatically to remain functional. Fourthly, our study is not based on longitudinal data analysis, that is, the results have been obtained only for one semester. The application of dynamic analysis could enable us to reinforce our conclusions and to investigate other unexplored issues such as the processes of creation and removal of student's ties. Finally, our study considered friendship network coreness as control variable. Our results indicate a possible negative influence of this variable on academic performance thereby suggesting the need to deepen the study of these effects and other possible interactions. Exploring all these limitations will provide us with the framework for future lines of research.

\section{References}

Allen, W. R., \& Haniff, N. Z. (1991). Race, gender, and academic performance in US higher education. In W. R. Allen, E. G. Epps, \& N. Z. Haniff (Eds.), College in Black and White: African American students in predominantly White and in historically Black public universities (pp. 95-110). Albany: State University of New York Press.

Amabile, T. M. (1996). Creativity in context. Boulder, CO: Westview Press.

Baldwin, T. T., Bedell, M. D., \& Johnson, J. L. (1997). The social fabric of a team-based M.B.A. program: Network effects on student satisfaction and performance. Academy of Management Journal, 40, 13691397.

Beck, R. J., Fitzgerald, W. J., \& Pauksztat, B. (2003). Individual behaviors and social structure in the development of communication networks of self-organizing online discussion groups. In B. Wason, S. Ludvigson, \& U. Hoppe (Eds.), Designing for change in networked learning environments (pp. 313322). Dordrecht: Kluwer.

Biancani, S., \& McFarland, D. A. (2013). Social networks research in higher education. In M. B. Paulsen (Ed.), Higher education: Handbook of theory and research (pp. 151-215). Netherlands: Springer.

Borgatti, S. P., \& Everett, M. G. (1999). Models of core/periphery structures. Social networks, 21(4), 375-395.

Borgatti, S. P., Everett, M. G., \& Freeman, L. C. (2002). Ucinet for Windows: Software for Social Network Analysis. Natick, MA: Analytic Technologies. 
Cattani, G., \& Ferriani, S. (2008). A core/periphery perspective on individual creative performance: Social networks and cinematic achievements in the Hollywood film industry. Organization Science, 19(6), 824-844.

Chen, B., Wang, F., \& Song, J. (2012). Are they connected? Exploring academic and social networks among MPA students at a Chinese University. Journal of Public Affairs Education, 18(1), 137-156.

Cho, H., Gay, G., Davidson, B., \& Ingraffea, A. (2007). Social networks, communication styles, and learning performance in a CSCL community. Computers \& Education, 49(2), 309-329.

Costantino, T., Kellam, N., Cramond, B., \& Crowder, I. (2010). An Interdisciplinary Design Studio: How Can Art and Engineering Collaborate to Increase Students' Creativity? Art Education, 63(2), 49-53.

Dawson, S. (2008). A study of the relationship between student social networks and sense of community. Educational Technology \& Society, 11(3), 224-238.

Dayioğlu, M., \& Türüt-Aşik, S. (2007). Gender differences in academic performance in a large public university in Turkey. Higher Education, 53(2), 255-277.

Erickson, B. H., Nosanchuk, T. A., \& Lee, E. (1981). Network sampling in practice: Some second steps. Social Networks, 3, 127-136.

Freeman, L. C. (1979). Centrality in social networks. Conceptual clarification. Social Networks, 1, 215-239.

French, J. R. P., \& Snyder, R. (1959). Leadership and interpersonal power. In D. Cartwright (Ed.), Studies of social power. Ann Arbor, MI: Institute for Social Research.

Gašević, D., Zouaq, A., \& Janzen, R. (2013). Choose your classmates, your GPA is at stake!: The association of cross-class social ties and academic performance. American Behavioral Scientist, 57(10), 1460-1479.

Guimerà, R., Uzzi, B., Spiro, J., \& Amaral, L. A. N. (2005). Team assembly mechanisms determine collaboration network structure and team performance. Science, 308(5722), 697-702.

Haythornthwaite, C. (2002). Strong, weak, and latent ties and the impact of new media. Information Society, 18, $385-401$.

Hommes, J., Rienties, B., Grave, W. D., Bos, G., Schuwirth, L., \& Scherpbier, A. (2012). Visualising the invisible: a network approach to reveal the informal social side of student learning. Advances in Health Education, 17(5), 743-757.

Hoskins, S. L., Newstead, S. E., \& Dennis, I. (1997). Degree performance as a function of age, gender, prior qualifications and discipline studied. Assessment \& Evaluation in Higher Education, 22(3), 317-328.

Huang, L. (2009). Social capital and student achievement in Norwegian secondary schools. Learning and individual differences, 19(2), 320-325.

Ibarra, H. (1993). Personal networks of women and minorities in management: A conceptual framework. Academy of Management Review, 18(1), 56-87.

Ibarra, H. (1995). Race, opportunity, and diversity of social circles in managerial networks. Academy of management journal, 38(3), 673-703.

Johnson, D. W., \& Johnson, R. T. (1993). Structuring groups for cooperative learning. Mastering management education: Innovations in teaching effectiveness. Newbury Park, CA: Sage.

Kassim, M. A., Hanafi, R. M., \& Hancock, D. R. (2008). Test anxiety and its consequences on academic performance among university students. Advance in Psychology Research, 53, 75-95.

Kornbrot, D. E. (1987). Degree performance as a function of discipline studied, parental occupation and gender. Higher Education, 16(5), 513-534.

Kronegger, L., Ferligoj, A., \& Doreian, P. (2011). On the dynamics of national scientific systems. Quality \& Quantity, 45(5), 989-1015.

Lave, J., \& Wenger, E. (1991). Situated learning: Legitimate peripheral participation. Cambridge: Cambridge University Press.

Leydesdorff, L., \& Wagner, C. S. (2008). International collaboration in science and the formation of a core group. Journal of Informetrics, 2(4), 317-325.

Martens, K., \& Starke, P. (2008). Small country, big business? New Zealand as education exporter. Comparative Education, 44(1), 3-19.

McKenzie, K., \& Schweitzer, R. (2001). Who Succeeds at University? Factors predicting academic performance in first year Australian university students. Higher Education, 20(1), 21-33.

Meece, J. L., Anderman, E. M., \& Anderman, L. H. (2006). Classroom goal structure, student motivation, and academic achievement. Annual Review of Psychology, 57, 487-503.

Morrison, A., \& Rabellotti, R. (2005). Knowledge and Information Networks: Evidence from an Italian Wine Local System. Working Paper 174/2005, CESPRI, Università Bocconi, Milano.

Pekrun, R., Elliot, A. J., \& Maier, M. A. (2009). Achievement goals and achievement emotions: Testing a model of their joint relations with academic performance. Journal of Educational Psychology, 101, 115-135. 
Perry-Smith, J. E., \& Shalley, C. E. (2003). The social side of creativity: A static and dynamic social network perspective. Academy of management review, 28(1), 89-106.

Power, C., Robertson, F., \& Baker, M. (1987). Success in higher education. Canberra: Australian Government Publishing Service.

Raven, B. H. (1965). Social influence and power. In I. D. Steiner \& M. Fishbein (Eds.), Current studies in social psychology. New York: Holt, Rinehart \& Winston.

Rizzuto, T. E., LeDoux, J., \& Hatala, J. P. (2009). It's not just what you know, it's who you know: Testing a model of the relative importance of social networks to academic performance. Social Psychology of Education, 12, 175-189.

Schilling, M. A. (2005). A 'small-world' network model of cognitive insight. Creativity Research Journal, 17(23), 131-154.

Smith, J., \& Naylor, R. (2001). Determinants of degree performance in UK universities: a statistical analysis of the 1993 student cohort. Oxford Bulletin of Economics and Statistics, 63(1), 29-60.

Smith, R. A., \& Peterson, B. L. (2007). "Psst ... What do you think?". The relationship between advice prestige, type of advice, and academic performance. Communication Education, 56(3), 278-291.

Sparrowe, R. T., Liden, R. C., Wayne, S. J., \& Kraimer, M. L. (2001). Social Networks and the Performance of Individuals and Groups. Academy of Management Journal, 44(2), 316-325.

Stassen, M. L. A. (2003). Student outcomes: The impact of varying living-learning community models. Research in higher education, 44(5), 581-613.

Thomas, S. L. (2000). Ties that bind: A social network approach to understanding student integration and persistence. Journal of Higher Education, 71(5), 591.

Uzzi, B., \& Spiro, J. (2005). Collaboration and Creativity: The Small-World Problem. American journal of sociology, 111(2), 447-504.

Wasserman, S., \& Faust, K. (2007). Social Network analysis: Methods and applications. Cambridge: Cambridge university Press.

Yang, H. L., \& Tang, J. H. (2003). Effects of social network on student performance: Web-based forum study in Taiwan. Journal of Asynchronous Learning Network, 7(3), 93-107.

Yin, R. K. (1989). Case Study Research, Design and Methods. Beverly Hills: Sage.

Yuan, Y. C., Gay, G., \& Hembrooke, H. (2006). Focused activities and the development of social capital in a distributed learning “community”. The Information Society, 22(1), 25-39. 
Table 1. Sample characteristics

\begin{tabular}{l|cc}
\hline & NCD & CD \\
\hline Number of male students & $38(50,00 \%)$ & $31(39,74 \%)$ \\
Number of female students & $38(50,00 \%)$ & $47(60,26 \%)$ \\
Average age & $22.13($ S.D. $=1.06)$ & $23.03($ S.D. $=1.49)$ \\
$\begin{array}{l}\text { Students grade point average } \\
\text { (based on a 10-point scale) }\end{array}$ & $7.82($ S.D. $=1.08)$ & $7.62($ S.D. $=0.78)$ \\
\hline
\end{tabular}

Table 2. Descriptive statistics and correlations of the measurements in NCD sample

\begin{tabular}{|c|c|c|c|c|c|c|c|}
\hline Variables & Mean & SD & 1 & 2 & 3 & 4 & 5 \\
\hline (1) Academic performance & 7.819 & 1.080 & 1 & & & & \\
\hline (2) Academic network coreness & 0.129 & 0.076 & $0.396 * *$ & 1 & & & \\
\hline (3) Friendship network coreness & 0.105 & 0.072 & -0.080 & $0.467 * *$ & 1 & & \\
\hline (4) Student gender & 1.500 & 0.505 & -0.195 & -0.091 & 0.106 & 1 & \\
\hline (5) Student age & 22.130 & 1.063 & 0.062 & -0.085 & -0.057 & -0.051 & 1 \\
\hline
\end{tabular}

Note: $N=76 ; * * p<0.05$

Table 3. Descriptive statistics and correlations of the measurements in CD sample

\begin{tabular}{lccccccc}
\hline Variables & Mean & SD & 1 & 2 & 3 & 4 & 5 \\
\hline (1) Academic performance & 7.619 & 0.785 & 1 & & & & \\
(2) Academic network coreness & 0.130 & 0.032 & $0.339 * *$ & 1 & & & \\
(3) Friendship network coreness & 0.126 & 0.050 & 0.097 & $0.662 * *$ & 1 & & \\
(4) Student gender & 1.400 & 0.493 & -0.274 & -0.203 & -0.188 & 1 & \\
(5) Student age & 23.030 & 1.486 & -0.183 & -0.181 & -0.251 & 0.101 & 1 \\
\hline
\end{tabular}

Note: $N=78 ; * * p<0.05$

Table 4. Structural characteristics of the networks

\begin{tabular}{lcc}
\hline \multirow{2}{*}{ Measures } & \multicolumn{2}{c}{ Academic network } \\
\cline { 2 - 3 } & NCD & CD \\
\hline Average density & 0.215 & 0.227 \\
Isolated nodes & 0 & 0 \\
Gini index & 0.285 & 0.244 \\
\hline
\end{tabular}

Table 5. Core/periphery structure: densities within groups

\begin{tabular}{lcccc}
\hline & \multicolumn{2}{c}{ NCD } & \multicolumn{2}{c}{ CD } \\
\cline { 2 - 5 } & Core & Periphery & Core & Periphery \\
\hline Core & 0.623 & 0.181 & 0.647 & 0.163 \\
Periphery & 0.255 & 0.108 & 0.289 & 0.097 \\
\hline
\end{tabular}


Table 6. Regression results of models

\begin{tabular}{lll}
\hline Dependent variable: Academic performance & \multicolumn{1}{c}{ NCD } & \multicolumn{1}{c}{ CD } \\
\hline Academic network coreness & $0.552(3.964)^{* * *}$ & $0.439(2.799)^{* * *}$ \\
Academic network coreness squared & $-0.103(-0.722)$ & $-0.264(-2.099)^{* *}$ \\
Friendship network coreness & $-0.368(-2.363)^{* *}$ & $-0.220(-1.360)$ \\
Student gender & $-0.079(-0.607)$ & $-0.164(-1.286)$ \\
Student age & $0.099(0.807)$ & $-0.144(-1.190)$ \\
Model $F$ & $3.765^{* * *}$ & $4.240^{* * *}$ \\
$R^{2}$ & 0.274 & 0.290 \\
Adjusted $R^{2}$ & 0.201 & 0.221 \\
$N$ & 76 & 78 \\
\hline
\end{tabular}

Notes: Standardized regression estimates ( $t$-values)

$* p<0.1 ; * * p<0.05 ; * * * p<0.01$

Fig. 1. Academic networks in NCD (left) and CD (right) samples
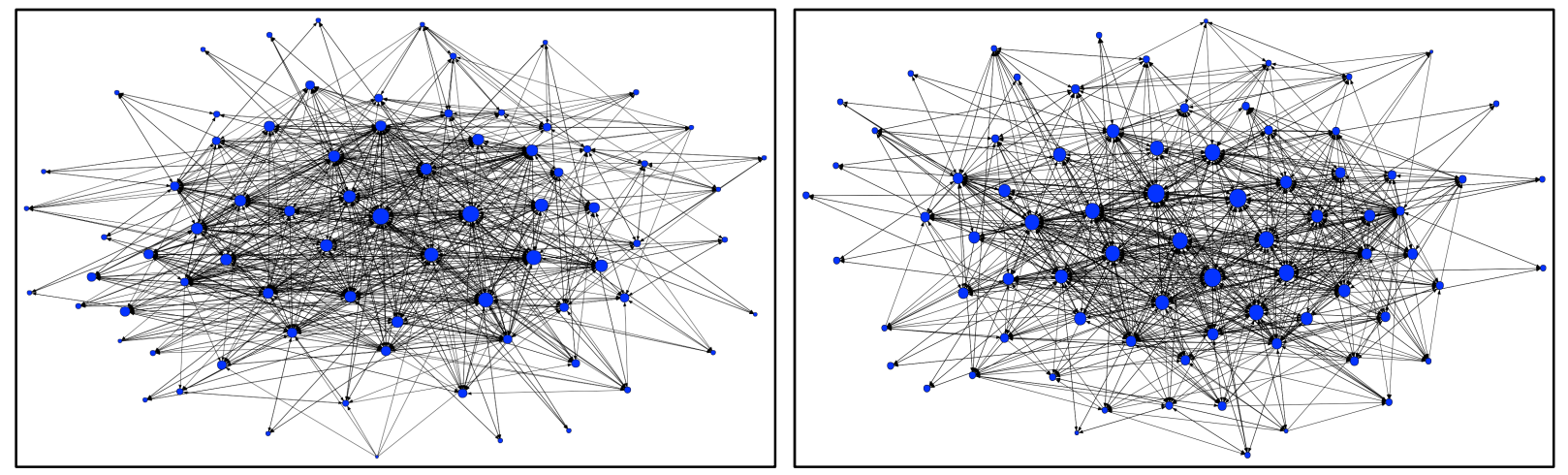

Fig. 2. Effects in NCD and CD samples

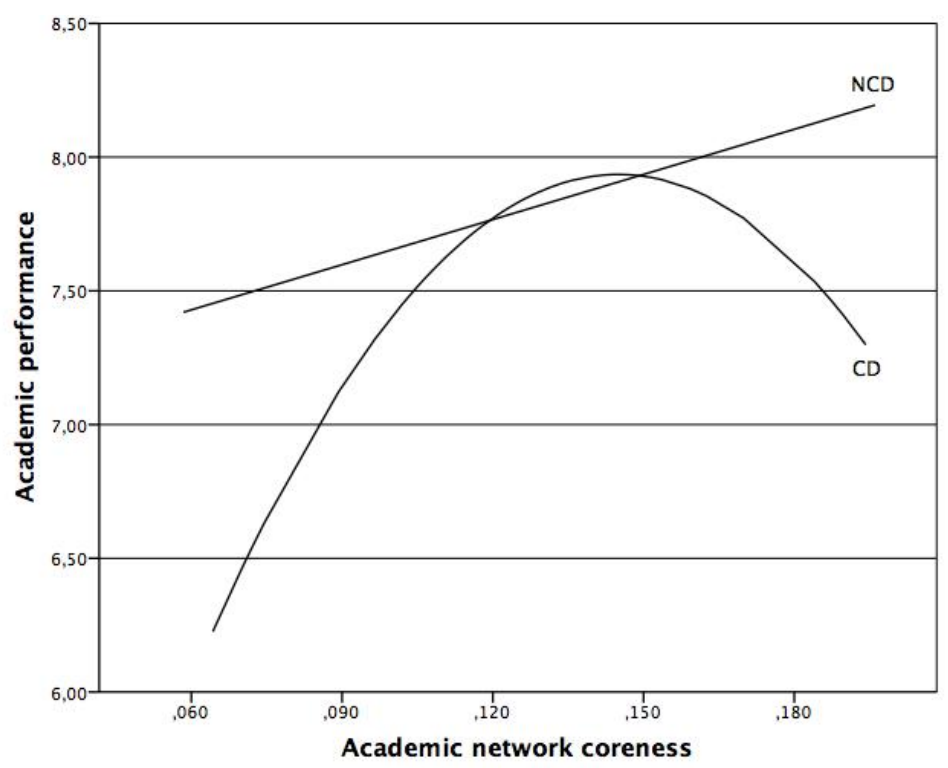

